Ori Freiman:

\title{
Towards the Epistemology of the Internet of Things
}

Techno-Epistemology and Ethical Considerations Through the Prism of Trust

\begin{abstract}
:
This paper discusses the epistemology of the Internet of Things [IoT] by focusing on the topic of trust. It presents various frameworks of trust, and argues that the ethical framework of trust is what constitutes our responsibility to reveal desired norms and standards and embed them in other frameworks of trust. The first section briefly presents the IoT and scrutinizes the scarce philosophical work that has been done on this subject so far. The second section suggests that the field of epistemology is not sufficiently capable of dealing with technologies, and presents a possible solution to this problem. It is argued that knowledge is not only social phenomena, but also a technological one, and that in order to address epistemological issues in technology, we need to carefully depart from traditional epistemic analysis and form a new approach that is technological (termed here Techno-Epistemology). The third and fourth sections engage in an epistemic analysis of trust by dividing it in to various frameworks. The last section argues that these various frameworks of trust can be understood to form a trustworthy large-scale socio-technological system, emphasizing the place of ethical trust as constituting our commitment to give proper accounts for all of the other frameworks.
\end{abstract}

\section{Agenda:}

A Lack of an Adequate Epistemic Framework for Analyzing the IoT ..................................... 9

A Departure from Common and Accepted Views of Knowledge: the Example of Network Epistemology and the Generation and Distribution of Knowledge................................................. 9

The Quests of Individual and Social Epistemology …................................................................ 10

Departing From Traditional Epistemology ...............................................................................

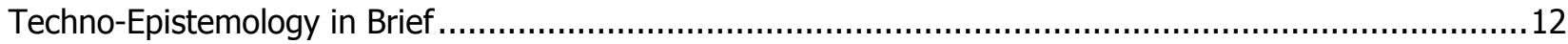

Knowledge Generation and Distribution: Epistemic Differences Between Social and

Technological Analysis

Trust as a Cornerstone Characteristic in the Construction of the IoT .................................. 13

The Trust-Reliance Distinction and Non-Moral Epistemic Agents .................................................13

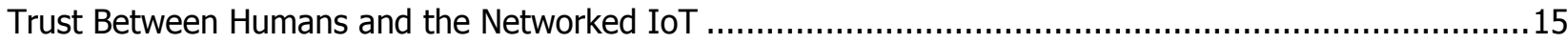

The Formation of Epistemic Trust Between Humans and the IoT ....................................................15

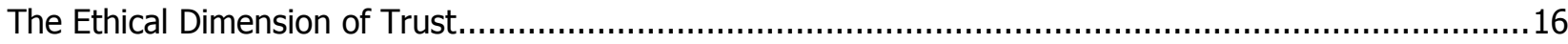

The Formation of Social Trust Between Humans and the IoT ........................................................16

Techno-Trust by a Reputation Cloud ................................................................................... 17

Conclusion: The Formation of Trustworthiness in Large-Scale Socio-Technological Systems..... 18 


\section{Author:}

Ori Freiman

- Ph.D. Candidate, The Graduate Program in Science, Technology and Society, Bar-Ilan University, Ramat-Gan, Israel

- $\square$ freimano@post.bgu.ac.il

\section{Acknowledgments:}

I thank Boaz Miller, Michelle Spektor, Talia Fried, Michael Eldred, Felix Weil and two anonymous reviewers for their useful comments and suggestions. 
This paper discusses the epistemology of the Internet of Things [IoT] by focusing on the topic of trust. It presents various frameworks of trust, and argues that the ethical framework of trust is what constitutes our responsibility to reveal desired norms and standards and embed them in other frameworks of trust. The structure of the article is as follows: The first section briefly presents the IoT and scrutinizes the scarce philosophical work that has been done on this subject so far. More generally, I argue that an adequate epistemic theoretical framework that deals with technology has not yet been developed. The second section suggests that the field of epistemology is not sufficiently capable of dealing with technologies, and presents a possible solution to this problem. I argue that in order to address epistemological issues in technology, we need to carefully depart from traditional epistemic analysis and form a new approach that is technological (termed here Techno-Epistemology). The third and fourth sections engage in an epistemic analysis of the concept of trust by dividing it in to various frameworks (referred to here as layers). The last section argues that these various layers of trust can be understood to form a trustworthy large-scale socio-technological system [LSSTS], emphasizing the place of ethical trust as constituting our commitment to give proper accounts for all of the other layers.

More specifically, the second section introduces individual epistemology's quest for justification in order to acquire knowledge, and its relatively recent development of social analysis. Building upon Paul Humphreys' (2009) framework of Network Epistemology, this section criticizes both individual and social epistemology for being anthropocentric, and argues that this renders individual and social epistemology unsuitable for a proper epistemic analysis of technology. An alternative framework to traditional epistemic analysis, namely TechnoEpistemology, is introduced and applied to the IoT. By presenting the concept of Scientific Instruments of Things [SIoT], a hybrid view of scientific knowledge generation and distribution, for both human and nonhuman epistemic agents and their related social and technological processes, is suggested. Epistemic differences between networks of humans and machines are highlighted in order to raise a dual question of trust: how will humans trust the network of the IoT, and how can justified relations of trust form between scientists and the SIoT?

The third section deals with various layers of trust. Beginning with the trust-reliance distinction, the fundamental question of whether or not trust relationships between humans (as moral agents) and non-humans (as nonmoral agents) are possible, is discussed. McDowell's (2002) distinction between epistemic trust and social trust is presented, and Lehrer's (1995) and Sosa's (2006) accounts of trust are offered in order for human users and scientists to epistemically trust the IoT and the SIoT. Next, the ethical dimension of trust is identified as the "unseen link" between epistemic trustworthiness and norms and standards. I argue that norms and standards should be the focal-points in trust formation. A recent discussion about the topic of trust in the context of the IoT (Kounelis et al. 2014) and Nickel's (2013) Entitlement Account, which addresses direct trust in artifacts, are brought forward as examples for social processes that can set the technological norms and standards, and also as a suggestion of the formation of social trust in the context of technology and knowledge.

The fourth section discusses techno-trust ${ }^{1}$ between IoT devices. As a general example, I suggest the formation of a reputation system for the IoT and SIoT devices. This system will not only present evidence for trustworthiness for these devices, but will also form a rational basis of trust for human users of the IoT and SIoT. The main argument is twofold, and normative: A) An adequate theoretical systematic epistemic framework that analyses technology must be developed, and B) The ethical layer of trust is what constitutes our responsibility to reveal desired norms and standards and embed them in other frameworks of trust in order to form a trustworthy LSSTS.

\footnotetext{
${ }^{1}$ For methodological reasons epistemological concepts are distinguished from those of the Techno-Epistemological framework by the prefix "techno-".
} 


\section{A Lack of an Adequate Epistemic Framework for Analyzing the IoT}

The IoT is one of the most popular technology-buzzwords, and with good reason. As an infrastructure upon which many applications and services function, the IoT is based on the idea of connectivity, for any thing, any place, and any time. It represents real-world objects that are connected in a network, continuously sensing, collecting, processing and communicating. When it is joined with technologies that enable ultra-fast connection, and that of cloud computing (the idea of providing centralized computer-related services), vast amounts of storage memory and processing power are available to the clients - whether they are humans or machines ${ }^{2}$. The idea is not only to transmit live data, for example, the heart rate of a patient to her doctor, but to be able to correlate real-time potential events with similarities, correlations, and abnormalities present in the "big data" that were processed and mediated through many IoT devices ${ }^{3}$. While the IoT's sensors "act as the digital nerves for connected devices, the cloud can be seen as the brain to improve decision-making and optimization for internet-connected actions related to these devices" (van den Dam 2013).

As technology and technological solutions advance over time, the overlap and convergence between various fields of applications (and studies) increase. The IoT represents this kind of convergence and overlap (together with cloud computing and ultra-fast broadband network connectivity, as mentioned, among other infrastructure technologies) by increasing the amount and sophistication of sensing, processing, and communicating, ultimately enabling us to create knowledge from the vast amounts of collected real-world measurements (Stankovic 2014). These technologies already have many applications and its potential applications reach all areas of life (for many examples, see ERCIT 2012 and references within). The IoT devices are estimated to soon become the largest device market in the world ${ }^{4}$. However, the realm of philosophy still has not provided an epistemic account for the IoT.

By the same token, an epistemic theory within the Anglo-American analytic philosophical traditions, which deals with technology in general, has also not yet been developed ${ }^{5}$. Such a theory would ultimately enable reflections about technological epistemology to be integrated into the philosophical and technical corpus. Since the working assumption of epistemology is that knowledge is binary (true or false), and that justification is a matter of degree, the more technological knowledge a person has, i.e. "knowledge that is involved in the designing, making and using of technical artifacts and systems" (Meijers \& De Vries 2009, p. 70), the more a person can justify and defend the acceptance of a belief that was formed through the technological artifact. This means that the successful application of an epistemological framework that analyzes technology must take technological knowledge into its considerations. Nevertheless, technological knowledge was intellectually-historically neglected (Laudan 1984), and as Meijers \& De Vries (2009, p. 70) note, "reflections on the nature of technological knowledge are fairly recent in the philosophy of technology. In more general epistemological debates, technological knowledge hardly ever features as an object of serious considerations". This paper constitutes an initial step in remedying this situation.

\section{A Departure from Common and Accepted Views of Knowledge: the Example of Network Epistemology and the Generation and Distribution of Knowledge}

After the IoT has been introduced and it was argued that knowledge in technological contexts hardly ever features epistemological analysis, this section suggests a reason for the lack of epistemic involvement in the

\footnotetext{
${ }^{2}$ For technical details see Hassan, Song, \& Huh (2009) and Yuriyama \& Kushida (2010).

3Jaffe, Mark. 2014. "IoT Won't Work Without Artificial Intelligence", Wired November 12, 2014. http://www.wired.com/2014/11/iot-wontwork-without-artificial-intelligence/

${ }^{4}$ Greenough, John. 2014. "The 'Internet of Things' Will Be The World's Most Massive Device Market and Save Companies Billions of Dollars", Business Insider November 5, 2014. http://www.businessinsider.com/how-the-internet-of-things-market-will-grow-2014-10

${ }^{5}$ Nevertheless, there are epistemologists who analyze technology and depart from common traditional views. This point will be further discussed in $\S 2.2$.
} 
analysis of technology. It also attempts to remedy this situation with an initial epistemic comparison between human networks and networks of devices, and the analysis of IoT and Trust. Traditional views of epistemology are argued to lack the ability of analyzing current and future networked technologies, such as the IoT and SIoT. In contrast, a new kind of epistemological approach, Techno-Epistemology, is presented as a means to epistemically analyze technologies. It is argued that knowledge is not only a social phenomenon, but also a technological one. This section concludes with pointing out some epistemic differences between a group of humans and a group of networked devices, such as the IoT or SIoT, in order to lay the groundwork for the next sections to discuss the concept of trust, in a technological sense, and reveal the ethical considerations we must take in respect to trust in the IoT. Let us begin by briefly presenting the historical development of individual and social epistemology, and one of its criticisms, namely anthropocentric bias.

\section{The Quests of Individual and Social Epistemology}

Defined widely, epistemology is the study of knowledge. Though various kinds of knowledge exist, such as knowing a place, a person, or how to do something (like swimming), the scholarly interests of Anglo-American analytic epistemologists traditionally focus more narrowly - on the knowledge of propositions. (Steup 2014) That is, if people know what they believe, they would easily agree that a subject $S$ knows a proposition $P$ only if $S$ believes that $P$. However, since Greek antiquity, a belief is not considered to be a sufficient condition. Since then, it was generally agreed that a subject $S$ knows a proposition $P$ only if $S$ believes $P$, and in addition - that $P$ is true. Similar to Socrates's arguments in Meno and in the Theatetus, if a person, out of the blue, superstitiously, or luckily guesses something that happens to be true, we would not consider the true belief as knowledge. The true belief must be tied to something else - a justification. Epistemologists referred to justification as that missing "something else", and as part of the three conditions for knowledge - justified, true belief [JTB].

After centuries of absence from intellectual discourse, the problem of what that "something else" is - has reemerged. The JTB account of knowledge was refuted by Edmund Gettier's (1963) influential (among epistemologists) paper which introduced counter-examples to the (then) widely-accepted view. Gettier's argument, that one can have a JTB that is not knowledge, sparked the interest of epistemologists. Ever since, many new theories of knowledge were, and still are, being proposed, and have attempted to add more conditions or change the notion of justification. ${ }^{6}$

It was only relatively recently that philosophers began to engage with social epistemology ${ }^{7}$. Social epistemology deals with the social dimensions of knowledge. Generally, the term "knowledge", in its social sense, refers to epistemic content that has passed social processes, but the meanings of "social" and "knowledge" are both debatable. Scholars of social epistemology can be placed on a spectrum: those whose work is in keeping with the tenets of traditional individual epistemology, and those who depart from it. The first are referred to as classical social epistemologists or as the orthodox camp. They focus on concepts such as truth and rationality, and the ways in which an individual acquires knowledge or justified belief in social contexts. They build upon individual (general) epistemology and extend its scope to the social. The latter, anti-classical social epistemologists, or reformists, hold that knowledge, similar to language, is found within a community. They focus on collective doxastic agents or groups as another ontological level of knowledge bearing. The more extreme trends on this side of the spectrum, the revisionist camp, even reject the traditional focus on concepts such as justification or rationality. They "posit the social, practical, and empirical fruits of inquiry, rather than truth, as the standards of normative epistemic appraisal" (Miller forthcoming).

\footnotetext{
${ }^{6}$ This phenomenon has received an epithet label within scholar discussions, academic syllabuses, and publications - Gettierology. See Shope (1983) for the intellectual history of this quest.

${ }^{7}$ For the development of social epistemology, see Goldman \& Blanchard (2012) and Miller (forthcoming).
} 


\section{Departing From Traditional Epistemology}

Dealing with a wide variety of sources and processors of knowledge and justifications, such as sophisticated scientific instruments or computer software, significantly affects "our notion of science and scientific interpretation of the world, driving at the same time the philosophical debate[s]" (Primiero 2014, abstract). To a large extent, part of our knowledge, like many of our beliefs, is acquired, transmitted, generated, and mediated in and through technologies. Various scholars, theories, and approaches, outside of traditional epistemology attribute morality or the ability to know to technological artifacts. These views can be found within the fields of machine ethics (Torrance 2009), artificial intelligence (Tonkens 2009), and information ethics (e.g. Capurro 2000; Capurro \& Hjørland 2003; Wallach \& Allen 2009; Floridi \& Sanders 2004). These views are also held by a number of scholars in Science and Technology Studies (e.g. Winner 1985; Latour 1992), phenomenologist philosophy, as well as some scholars who deal with information communication technologies. While attributing technology with the ability to know may be trivial to many scholars, traditional Anglo-American analytic epistemology, whether individual or social, does not attribute knowledge to artifacts. Individual epistemology concepts such as belief, proposition, memory, and causal reasoning, as well as social epistemology concepts such as testimony, evidence, and trust, are anthropocentric.

To a lesser degree, the ability to outsource knowledge (and understanding) to digital devices (e.g. via algorithms) is the defining feature of some philosophical approaches to technology (such as phenomenological digital ontology, see Eldred 2011; Compton 2009). It can be said that an analog to this outsourcing is found within the field of epistemology: some reformist social epistemologists do accept that mental states and cognitive processes extend beyond our organisms to other humans and artifacts ${ }^{8}$. As some scholars utilize traditional concepts, in general, to analyze knowledge from technology (e.g. Kourken 2014; Record 2013), this kind of analysis is not commonly found and is mostly believed to be limited. For example, David Coady, whose focus is applied epistemology, wrote in the preface to his (2012) book What to Believe Now.

The information revolution and the knowledge economy have radically changed the way that we acquire knowledge and justify our beliefs. These changes have altered our epistemic landscape as surely as the sexual revolution and breakthroughs in reproductive technology have changed our moral landscape. The latter changes provided a good deal of the impetus for the applied turn in ethics, but the former changes have so far failed to result in a comparable turn in epistemology. Such a turn is surely inevitable. (p. 2, emphasis added)

Given the wide range of approaches to the relationship between technology and knowledge, how can epistemologists consider the place of technologies in various epistemic processes? Humphreys (2009) criticizes individual and social epistemological frameworks for being "infused with anthropocentric concepts" (p. 221). His criticism, based on the view that epistemology might be outdated, argues that today's technologies are looked to and used as sources of knowledge, as if they possess it: "[...] we do speak of computers storing and processing knowledge as well as information, language that is not just metaphorical. Printed books contain knowledge and so do their on-line versions" (ibid).

Revisionist social epistemologists seek to revise traditional epistemic notions for the epistemic analysis of knowledge and technology. For example, Baird (2004) developed material epistemology, and argued that (some) scientific instruments are a form of material objective knowledge and referred to them as "thing knowledge". Among the properties of thing knowledge is that it expresses the knowledge of their designers. Therefore, among other implications, technological knowledge is not belief-based, but thing-based ${ }^{9}$ (for epistemic concerns, see Pitt 2007 and Kletzl 2014; for social concerns, see Cavicchi 2005). Other suggestions

\footnotetext{
${ }^{8}$ This is the internalism-externalism debate within epistemology regarding belief justifications that is parallel to the philosophy of mind internalism-externalism debate regarding the spatial location of cognitive processes and mental states (see Carter, Kallestrup, Palermos \& Pritchard 2014). Externalists mostly rely on the extended cognition hypothesis (Clark 2007), the extended mind thesis (Clark \& Chalmers 1998), and the distributed cognition hypothesis (Hutchins 1995).

${ }^{9}$ Within the phenomenological tradition, Eldred (2011, pp 61-62) recognizes know-how as a kind of understanding which is deeper than knowledge. He used a potato peeler as an example for outsourcing know-how knowledge (of peeling potatoes) to material design: "A
} 
include different Truth criteria, such as effectiveness or efficiency, have also been raised (e.g. Houkes 2006). Nevertheless, technological knowledge (see §1.) is described as "epistemologically unusual" (Ibid). This makes the analysis of knowledge from technology much more complex (see §3.3.)

\section{Techno-Epistemology in Brief}

Whether or not epistemological approaches are correct in adhering to an anthropocentric approach to technology, they are nevertheless capable of applying their (limited) analyses on issues of technology. As mentioned before (§2.2.), these kinds of analyses are not commonly found. As Miller \& Record (2013, p. 121) point out: "despite our vast and deep dependence on technology for acquiring knowledge and justified belief, epistemology has not, for the most part, given serious thought to the role technology plays in the fabric of knowledge and justification".

Some areas of science such as robotic astronomy, parts of experimental high energy physics, and parts of genomic analysis, can be said to present instruments that collect data that is processed by computers without any intervention by humans (Humphreys 2009). The trend of purely automated processes, carried out by scientific networks of instruments and computers, is increasing. The same thing could be said about the IoT and its usage within the scientific domain. Scientists and scholars will not only develop and discuss the IoT, but will also use it for their own research - as scientific instruments that create and measure phenomena. Let us refer to the IoT devices that can be applied to a scientific use, such as the aforementioned purely automated processes, as Scientific Instruments of Things [SIoT]. In order to epistemologically address the IoT, SIoT, and technologies in general, we need to carefully depart from the traditional individual and social epistemological layers of analysis, and without rejecting them form a new one - technological. Let us refer to this layer as Techno-Epistemology (see table 1).

Table 1. A Proposal for a New Epistemic Approach

\begin{tabular}{|l|c|l|c|}
\hline $\begin{array}{l}\text { Layers of } \\
\text { epistemic } \\
\text { analysis }\end{array}$ & \multicolumn{1}{|c|}{ Techno-Epistemology } \\
\hline $\begin{array}{l}\text { Unit of } \\
\text { analysis }\end{array}$ & Individual Epistemologist Epistemology & \\
\end{tabular}

Techno-Epistemology's layer of analysis can take into consideration the individual, social, and technological units of analysis.

\section{Knowledge Generation and Distribution: Epistemic Differences Between Social and Technological Analysis}

Miller \& Pinto (in progress) note three major, fundamental and widely-accepted views of the generation and distribution of scientific knowledge: Kitcher's (1990) description of apt division of cognitive labor among researchers, Longino's (2002) description of the social process of critical scrutiny and evaluation, such as peer review, that information must undergo in order to acquire the status of knowledge, and Hardwig's (1985) cornerstone paper about justified relations of trust among researchers.

This paper offers an in-principle epistemic symmetry between human and non-human epistemic agents regarding the generation and distribution of scientific knowledge. Since the generation and distribution of knowledge, in general, are not only social processes, but also technological processes, we are behooved to extend, or even revise, our epistemic views. A hybrid view of knowledge generation and distribution, for both human and nonhuman epistemic agents, as well as both the social and the technological processes involved, is needed in order to properly epistemically analyze technologies in general, and the IoT in particular. The future trend of SIoT

better potato peeler is the embodiment of a better, more efficient potato-peeling know-how" (p. 62). Within the analytic tradition, other examples for revisionist social epistemologists are, for example, Chang (2004) and Humphreys (2004). 
exemplifies technologies which take part in the generation and distribution of scientific knowledge. TechnoEpistemologica/ analysis that takes into account the major epistemic differences between networks of humans and machines, as Humphreys (2009) initially suggested, in the context of the networked devices of the IoT and the SIoT is proposed.

While no single scientist can directly access the knowledge of another peer, SIoTs may have direct access to networked knowledge. Also, the network of SIoT can perform a kind of a "thought transfer", to a degree that a device inside the network can reason or conclude from the data, information, or knowledge that is transferred, generated, or directly accessed through the network. Another major epistemic difference is the kind of subjectivity that is common among scientists' beliefs and background beliefs regarding scientific knowledge: while a humanitarian belief regarding science cannot always be explicitly expressed and communicated (and if so, it is sometimes considered subjective), the propositions of machines or models that take part in the SIoT can be explicitly expressed.

Finally, the network of the SIoT can, in principle, epistemically act as a single agent, while a community of scientists exchanging knowledge will not act as immediately and as directly as the networked SIoT. Given the differences between human networks and networks of IoT and SIoT, how can human users trust the networked devices of the IoT, and how can justified relations of trust form between scientists the SIoT?

\section{Trust as a Cornerstone Characteristic in the Construction of the IoT}

In the previous sections, this paper argued that individual and social epistemologies are anthropocentrically biased, and therefore insufficient for analyzing networked technologies. The framework of Techno-Epistemology was proposed as a third epistemic approach that can be used to analyze networked technologies such as the IoT and SIoT. The next section points out the ethical considerations of Techno-Epistemology through the prism of the topic of trust. It begins by presenting the commonly-found distinction between trust and reliance, and the various approaches that different fields of inquiry take toward it. I show that epistemology considers the possession of human qualities that enable morality to be a fundamental requirement for an epistemic agent to trust or to be trusted. Other accounts of agents that require human qualities to lesser extents are presented. By building on those other accounts, this paper presents the concepts of trust regarding epistemic agents in a way that avoids the anthropocentric bias of traditional epistemic requirements. This results in a different epistemological perspective that opens up for analysis conceptions of trust outside of the traditional relationships formed exclusively between human beings. In light of this perspective, the epistemic, social, and ethical layers of trust are discussed. Section 4 will present Techno-Trust in the context of the layers of trust discussed in Section 3, and Section 5 will conclude by presenting the formation of a trustworthy LSSTS.

\section{The Trust-Reliance Distinction and Non-Moral Epistemic Agents}

In recent years, the concept of trust has been widely discussed in many academic contexts and disciplines, mostly in computer science, management, and business ${ }^{10}$. Different applications and understandings of trust have developed across the many fields in which it is discussed. In epistemology, the topic of trust is mostly discussed within the context of testimonial accounts of knowledge ${ }^{11}$, though "there are a number of philosophical questions that arise in relation to the concept of trust, both because of the intrinsic interest of the topic, and also because it is so fertile a perspective from which to approach different topics related to the way we live together" (Simpson 2012, p. 566). ${ }^{12}$

\footnotetext{
${ }^{10}$ As indicated by Thomson Reuters' Web of Science. Search criteria: Topic: "Trust", Timespan: All years, Indexes: SCI-EXPANDED, SSCI, A\&HCI, CPCI-S, CPCI-SSH.

${ }^{11}$ Though the concept of testimony is not elaborated in this paper, it is shortly discussed in $\S 4$ and footnotes 16 and 18.

${ }^{12}$ Simpson (2012) notes that "the philosophical literature on trust remains slim indeed" (p. 550), that "there is no single phenomenon that 'trust' refers to" (p. 551), and makes the case that the concept of trust is not amenable to conceptual analysis as it is as an umbrella
} 
The spectrum of the extent to which a notion of trust can be applied to non-humans - such as technological artifacts, scientific instruments, or even LSSTS's - ranges according to the discipline's accepted views. As mentioned before (§2.2.), at one extreme, scholars within the field of Science and Technology Studies [STS] argue that technological artifacts possess a form of agency of their own (canonical examples are Winner 1985 and Latour $1992^{13}$ ). In the corpora of a few disciplines, such as information ethics (e.g. Wallach \& Allen 2009; Floridi \& Sanders 2004), machine ethics (Tonkens 2009), and artificial intelligence (Torrance 2011), it is acceptable and common for a non-human epistemic agent to act as a moral agent, and therefore to be able to trust or be trusted (e.g. Tavani 2014).

At the other extreme, some philosophers of technology, famously influenced by Joseph Pitt's "technology is humanity at work" (2010, p. 445, originally emphasized; see 1983 for the original formulation) tend to take an opposite viewpoint, and reduce questions regarding trust in technologies to questions regarding trust in the humans which are "behind" these technologies, such as designers or engineers. Within normative ethics and epistemology discourses, the general and accepted view is that a human cannot form trust relationships with a non-moral agent. Trust, many hold, is founded on a human quality, such as rationality, consciousness, free will, intentionality, and so forth. For example, Jones (1996, p. 14) stated that "trusting is not an attitude that we can adopt toward machinery [...] One can only trust things that have wills, since only things with wills can have goodwills". The latter camp argues that though we cannot trust technological artifacts, we can rely on them: "reliance is way of acting, whereas trust is an attitude" (Nickel 2013, p. 224 fn 3). Trustworthiness, unlike reliability, is "the opportunity for the trustee to act against the wishes of the trustor and the trustee's consideration of the value of the trust that has been placed in them by the trustor" (Wright 2010, abstract).

The trust-reliance distinction, in its technological context, focuses on the question of whether or not trust relationships, involving both humans (as moral agents) and non-humans (as non-moral agents), are possible. Human qualities required for such a relationship, such as those stated above, are not (yet) possessed by technological artifacts, which cannot be considered as moral agents - and therefore cannot be considered trustable.

The late Edsger Dijkstra, a computer scientist, once said that "the question of whether machines can think [...] is about as relevant as the question of whether submarines can swim"14. The same could be said about many human activities. The case of trust exemplifies the limits of epistemology in its considerations of non-humans. More generally, "it seems that the difficulties [...] lie in the tendency of standard epistemology to analyze knowledge in terms of human beings' properties" (Miller \& Record, p. 121).

However, it is possible to build upon conceptual epistemological advances that have been made regarding technological artifacts. For example, Johnson (2006) does not consider technological artifacts to be moral agents, but argues that they do have "moral efficiency" and therefore qualify as "moral entities". Floridi (2011) argues that autonomous technological artifacts (what he terms Autonomous Artificial Agent) can be moral agents since they can function as "sources of moral action" and are able to cause moral good or harm (Tavani 2014). The corpus that has dealt with the question of whether a technological artifact can be considered a moral agent is large enough to advance non-traditional views of moral technological agents. For example, Johansson (2013) lists various views about the possibility of an action that can "originate inside an artifact, considering that it is, at least today, programmed by a human" (p. 295).

Whether or not Techno-Epistemology, as a new epistemic layer of analysis, departs from the anthropocentric conceptions prevalent in individual and social epistemology and treats technological artifacts as epistemic agents, it can still analyze the role technology takes in knowledge and justification made by human(s). If it

term. I embrace this view; the various contents of the concepts of trust presented here are not necessary and sufficient conditions for a definition.

13 Though other STSers such as Bloor (1999) and Collins (2010) have argued that humans differ from non-humans in the context of justification.

${ }_{14}$ Dijkstra, Edsger W. 1984. "The threats to computing science", Lecture delivered at the ACM 1984 South Central Regional Conference, November 16-18, Austin, Texas, USA. Transcript available at http://www.cs.utexas.edu/users/EWD/transcriptions/EWD08xx/EWD898.html 
does depart from prevalent anthropocentric conceptions, it is inherent that the non-human epistemic agents (devices, instruments, algorithms, etc.), which can be regarded as outsourced human knowledge, can normatively expect that information from other sources be transmitted in a certain standardized form. ${ }^{15}$ Without rejecting individual and social epistemology, Techno-Epistemology holds that relations of techno-trust can be formed between two non-moral agents, and between non-moral and moral agents. It is possible only if an epistemic agent, human or not, expects information to be provided in certain forms, and its attitude is affected by the information received. This point will be further elaborated in light of social epistemology's concept of testimony in Section 4.

By presenting the trust-reliance distinction, the concept of trust was presented as polysemous among various disciplines. By avoiding the anthropocentric bias of traditional requirements for morality or human qualities, it is possible to discuss trust not only as a relationship between two human beings, but also between humans and devices, as well as between devices. The next section begins with a distinction between epistemic and social trust, and present ethical trust as a link between these two.

\section{Trust Between Humans and the Networked IoT}

McDowell (2002) distinguishes between epistemic trust and social trust, and argues that they are deeply related. While epistemic trust regards justification of beliefs in propositions made by an epistemic agent, social trust "[...] is trust that someone will act co-operatively, or with one's best interests in mind, and in accordance with the social mores of the society or situation in which the participants find themselves" (p. 54). For example: I epistemically trust Adam, a know-it-all character - his statements are (probably) true. I do not socially trust Adam that he will keep it to himself if I ask him about Michelle. I socially trust my library not to share my loan history list with advertisers from the local book industry. Social trust can raise the amount of information interaction, as it "involves moral, personal or cultural dependability, or some combination of these" (p. 54).

Part of the upcoming challenge is not only to construct the IoT devices to be epistemically trustworthy by indicating that its truth statements are right (i.e. epistemic trust), but also to construct the system, as a whole, as trustworthy (i.e. social trust). This challenge would likely involve a wide variety of characteristics to consider. Such a characteristic might be, for example, transparency regarding the relevant information and processes disclosed: "in order to critically assess epistemic agents, content and processes, we need to be able to access and address them" (Simon 2010, p. 343).

\section{The Formation of Epistemic Trust Between Humans and the IoT}

Lehrer (1995) offers the Evaluation Model of Instrumental Knowledge for explaining the structure of justification for trustworthiness. Among the essential features of instrumental knowledge, is the acceptance of the trustworthiness of the instrument and its output as truth. In order to know $p$ through the use of an instrument, a person must have a trustworthy basis for the evaluation of the belief and defend its acceptance against objections. But what is that trustworthy basis for the evaluation of the belief? Sosa (2006) presents an account of how not only our senses are reliable, but instruments as well ${ }^{16}$ : a non-human technological artifact is reliable when a human subject has an indication that the artifact indicates the truth outright and accepts that indication.

It is possible, then, to consider what a framework for the formation of epistemic trust in the IoT and SIoT might look like. In order for a human subject (or a scientist) $S$ to form epistemic trust in the IoT's (or in the SIoT's)

\footnotetext{
${ }^{15}$ For additional approaches which take this direction, see Buechner \& Tavani (2011).

${ }^{16}$ Sosa (2006) argues that testimonial knowledge presupposes instrumental knowledge by using the instrument of language. Consequently, instrumental knowledge, including testimonial knowledge, cannot be reduced to non-instrumental knowledge: "Our access to the minds of others is after all mediated by various instruments, and we must trust such media at least implicitly in accessing the testimony all around us" (p. 118, originally emphasized). For the contrary view, see Goldberg (2012). See also §4 and footnote 18 for more on testimony in technological context.
} 
devices' output, $S$ must have an indication that the device indicates the truth, and accepts that indication. In addition, $S$ must be able to defend the acceptance of the belief against objections. This means that knowledge regarding how the device resulted with its outcome, meaning technological knowledge, is needed.

\section{The Ethical Dimension of Trust}

The formation of trust is, in itself, ethical, but what is the ethical dimension of trust and what is its relation to epistemic and social trust? The ethical dimension of trust can serve as a link between epistemic and social trust. Wagenknecht (2014) argues that the moral dimension of trust does not involve doubts concerning the epistemic trustworthiness of a collaborator, i.e. the risk of doubts concerning the true or false value of a proposition. Instead, it involves "the deliberate will to take this risk and to resort to a number of measures that can mitigate it" (p. 85). By referring to "institutional trust, i.e. trust in community-borne gate-keeping functions, [the truster] can partly compensate for a lack of familiarity with potential collaborators" (ibid).

This lack of familiarity, which happens when a truster needs to co-operate with an unknown epistemic agent, forces trusters to rely on social norms and standards. Since trust is usually not something measured, but is rather an attitude expressed by one epistemic agent towards another, that attitude is mostly invisible. As Marsh \& Briggs (2009, p. 10) stated: "like light, trust is seen in its effect on something, and in between truster and trustee, there is simply nothing to see".

Kiran \& Verbeek (2010) argued that it is possible to actively engage in the technological processes that impact us. Trust, according to their argument, takes on the character of confidence: we trust ourselves to technology. This means our concern should be "how to take responsibility for the quality of technological mediations, and of our ways of living with these mediations" (p. 425). The ethical dimension of trust, which can be identified as the "unseen link" between epistemic trustworthiness and the social norms and standards which lets trusters take the risk of doubt, is where the challenge of social trust is focused: how can these social norms and standards be institutionalized, and how can they be embedded within the network of the IoT? Norms and standards are, after all, not only social but technological as well. The goal of making these norms and standards explicit, and the question of what are these norms and standards are, are left open for future experts, specialists, and users, to achieve and answer. With these answers it is possible to gain social, technological, and LSSTS kinds of trust.

\section{The Formation of Social Trust Between Humans and the IoT}

Kounelis et al. (2014) discuss the topic of trust in the context with the IoT. Their focus is not epistemological, but social and technical, mostly oriented toward democracy and security. By using the concept of "citizen", and not "user", they highlight that "the human capacity to maintain autonomy and control in a world of pervasive human-technological networking should be considered as an essential part of our ethical and legal endowment and entitlement in IoT" (p. 74). They suggest that by using a framework named SecKit (Security Kit), it is possible for citizens to adopt a collaborative approach to address various issues that regard the IoT, such as privacy or data protection (p. 77). Collaborations between humans, in order to pinpoint which technical and technological issues are important, increase the amount of information interaction, and form social trust between human users (or citizens, in Kounelis et al.'s case) and the IoT.

Nickel et al. (2010) recognize that any applicable notion of trustworthiness to technology must depart significantly from the notion of trustworthiness associated with interpersonal trust ${ }^{17}$. Nickel's (2013) account of trust involves trusting not only in the humans behind the technologies, but also in institutions. Though not all kinds of trust in technologies can be reduced to the humans and institutions behind them, he offers the Entitlement Account that makes sense of trust in technological artifacts. Two kinds of evidence will assure this kind of trust,

${ }^{17}$ See also Lahno (2004) for three accounts of interpersonal trust. 
by indicating that the designers have strong interests in serving the interests of the users: 1) A failure to perform will lead to an effective sanction by institutional structures, and 2) others are willing to stake their reputations on the technologies' performances. Both approaches exemplify how social processes can alter the technological norms and standards. In order to form relations of trust with technological artifacts and with the IoT in particular, we must pay constant attention not only to the social, but also the technological norms and standards which regard trust.

\section{Techno-Trust by a Reputation Cloud}

In the preceding sections, the formation of epistemic trust between humans and instruments, as well as the formation of social trust, were discussed. The ethical layer of trust was identified as the "unseen link" between the two. This section extends the ethical layer of trust by offering an epistemic account of trust between machines, referred to here as Techno-Trust. To exemplify Techno-Trust, I suggest a reputation system upon which IoT and SIoT can form evidence-based trust relations.

Goldberg (2012) rejected the possibility that a non-human can reliably receive testimony from instruments. According to his view, to "rely in belief-formation on another speaker is to rely on an epistemic subject, that is, on a system which itself is susceptible to epistemic assessment in its own right, whereas 'mere' instruments and mechanisms are not properly regarded as epistemic subjects in their own right, they are not susceptible to normative epistemic assessment" (p. 182, emphasis added). Goldberg distinguished between instrument-based beliefs and testimony-based beliefs. The latter belong to epistemic subjects in their own right, "susceptible to full-blooded normative assessment" (p. 191), and "sophisticated enough to satisfy the conditions on being appropriately assessed in terms of rationality and responsibility" (p. 194). Without rejecting this view, the epistemic approach of Techno-Epistemology in principle deals with testimonies received by non-human epistemic agents that are not "full-blooded"18.

Sometimes "a person is not trusting another person but is instead trusting the community to which they both belong to tell them whether or not trust can be given [...] If someone does not live up to the community expected standards, then [the trustee] receives bad reviews, lowering their reputation" (Lawrance 2009, p. 327). According to this view, whenever expectations are not met, the reputation of the trustee is lowered, and potential trusters would gradually cease to trust the poorly reviewed epistemic agent.

By adopting this reasoning, the suggestion is to form a reputation system for devices, which serves as a provider of explicit qualitative and objective measurements of the trustworthiness, as reflected by the characteristics of the device in question. This reputation system can be seen as a basis for the formation of techno-trust relations between devices of the IoT. Moreover, if evidence for trustworthiness is available to a human truster, a rational basis for trust can be formed (Simpson 2011; for the analysis of reputation as phenomenological phenomena, see Eldred 2013).

Since most interaction within the network of the IoT and SIoT is machine-to-machine interaction, the basic idea is to form a system that will assist devices in choosing their sources: the devices rate the interactions with each other on the basis of their observed and measured behavior, and base their interactions on these ratings. ${ }^{19}$ In this way, each device "consults" the reputation cloud for the necessary information that is crucial for its own decision making, beyond an evaluation of how well they perform the tasks they were designed for. For example, for one type of device, the normative expectation to get a result immediately might be the main characteristic of trust, while for another, the frequency of sensors calibration, or the kind of lens it has, might be the crucial factors for the automated decision making process. Through this method a device will improve (or worsen) its

\footnotetext{
${ }^{18}$ Miller \& Record (2013, p. 121, fn 3) correctly stated that "the question of whether and on what conditions information from computers and other instruments constitutes testimony has been largely overlooked". For exceptions, see references within and footnote 16 of this paper.

${ }^{19}$ For a survey of multi-agent trust models, see, e.g., Han et al. (2013); and for a survey of surveys, see Pinyol \& Sabater-Mir (2013).
} 
reputation for various functions, and thus acquire (or revoke) its ability to be techno-trusted by other IoT devices. ${ }^{20}$

\section{Conclusion: The Formation of Trustworthiness in Large-Scale Socio- Technological Systems}

Let us briefly recall the various accounts of rely and trust. Epistemic trust is assured by Sosa's (2006) Basis for the Evaluation of the Belief which holds that a technological artifact is reliable when a human subject has an indication that the artifact indicates the truth outright and accepts that indication. Building on the trustworthy basis for the evaluation of the belief, Lehrer's (1995) Evaluation Model of Instrumental Knowledge demands an ability to defend the acceptance of the belief against objections.

Social trust is exemplified by Kounelis et al.'s (2014) suggestion for citizens (human users) to maintain their autonomy and control by adopting a collaborative approach to address various social issues relating to the IoT. Social trust can also be ensured by Nickel's (2013) suggestion for evidence that humans behind the technologies, such as designers and manufacturers, have strong interest in serving the interests of the users. This can be indicated by effective sanctions levied by institutional structures, in the case of a failure, and by the fact that others are willing to stake their own reputation by using the technology. Both approaches exemplify how social norms and standards affect technological norms and standards.

The IoT devices rate the interactions with each other on the basis of their observed and measured behavior, and base their interactions on these ratings. This kind of reputation system presents evidence for trustworthiness, forming techno-trust between devices, and serves as a basis for the rational formation of trust in these devices by humans. The reputation system can be seen as the embedment of standards in the network of the IoT. The trustworthiness of a LSSTS, then, is assured by all layers of trust.

The main arguments were that an adequate theoretical, systematic epistemic framework that analyzes technology must be developed, and that the ethical layer of trust is what ties the other layers discussed in this paper. Ethical trust, or the deliberate will to take epistemic risks by referring to social trust, to use McDowell's (2002) distinction, is the dimension of trust which lets trusters take the risk of doubt by leaning on social norms and standards (Wagenknecht 2014). These social norms and standards affect technological norms and standards. It was claimed that trust is "unseen" (Marsh \& Briggs 2009) and that we have the responsibility to actively engage in technological processes (Kiran \& Verbeek 2010). Therefore, "unseen" desired norms and standards regarding trust, both social and technological, must be revealed, explicitly expressed, institutionalized, and embedded in the network of the IoT. They should be implemented in our collaborative use of technologies, the activities of institutions, and the design of technological artifacts. These norms and standards set the level of epistemic, social, technological, and LSSTS trust. The ethical dimension of trust constitutes a link between epistemic trust and other layers of trust. It constitutes our responsibility to reveal desired trust-related social and technological norms and standards and embed them in other frameworks of trust.

20See Marsh \& Briggs (2009) for formalizations, as computational concepts, of regret and forgiveness in the context of trust. For more on reputation in the context of the cyberworld, see special issue of International Review of Information Ethics, vol 19. 
Table 2. Frameworks of Trust

\begin{tabular}{|c|c|c|c|c|}
\hline \multirow{2}{*}{ Layers of trust } & \multicolumn{4}{|c|}{ Large-Scale Socio-Technological System } \\
\hline & Epistemic & Ethical & Social & Technological \\
\hline $\begin{array}{l}\text { Particular ac- } \\
\text { counts sug- } \\
\text { gested }\end{array}$ & $\begin{array}{l}\text { Sosa (2006), } \\
\text { Lehrer (1995) }\end{array}$ & $\begin{array}{l}\text { Marsh \& Briggs (2009), } \\
\text { Wagenknecht (2014), } \\
\text { Kiran \& Verbeek (2010) }\end{array}$ & $\begin{array}{c}\text { Kounelis et al. (2014), } \\
\text { Nickel (2013) }\end{array}$ & $\begin{array}{l}\text { Simpson (2011), } \\
\text { Lawrance (2009) }\end{array}$ \\
\hline Focus of trust & Instruments & $\begin{array}{l}\text { "Unseen" norms and } \\
\text { standards made explicit, } \\
\text { responsibility }\end{array}$ & $\begin{array}{l}\text { Collaborative ap- } \\
\text { proach, institutions' re- } \\
\text { gulations }\end{array}$ & Reputation cloud \\
\hline
\end{tabular}

The ethical layer of trust is bolded as this layer constitutes the link between epistemic trust and the other layers of trust. All accounts of trust form a trustworthy LSSTS.

\section{References}

Baird, Davis. 2004. Thing Knowledge: A Philosophy of Scientific Instruments. University of California Press. Bloor, David. 1999. "Anti-Latour", Studies in History and Philosophy of Science 30(1): 81-112.

Buechner, Jeff \& Tavani, Herman T. 2011. "Trust and multi-agent systems: applying the 'diffuse, default model' of trust to experiments involving artificial agents", Ethics and Information Technology, 13(1): 3951.

Capurro, Rafael \& Hjørland, Birger. 2003. "The Concept of Information", Annual Review of Information Science and Technology 37(1): 343-411.

Capurro, Rafael. 2000. "Hermeneutics and the phenomenon of information", In Metaphysics, Epistemology, and Technology. Research in Philosophy and Technology. Vol. 19, Carl Mitcham (ed.), JAI/Elsevier Inc. 2000, pp. 79-85.

Carter, A. J., Kallestrup, J., Palermos, O. S., \& Pritchard, D. 2014. "Varieties of Externalism", Philosophical Issues 24: 64-109.

Cavicchi, Elizabeth. 2005. "Thing Knowledge: A Philosophy of Scientific Instruments (review)", Technology and Culture 46(1): 243-245.

Chang, Hasok. 2004. Inventing Temperature. Measurement and Scientific Progress. Oxford: Oxford University Press.

Clark, Andy \& Chalmers, David. 1998. "The Extended Mind", Analysis 58: 7-19.

Clark, Andy. 2007. "Curing Cognitive Hiccups: A Defense of the Extended Mind", Journal of Philosophy 104: 163-192.

Coady, David. 2012. What to Believe Now: Applying Epistemology to Contemporary Issues. Wiley-Blackwell.

Collins, Harry M. 2010. "Humans not Instruments", Spontaneous Generations: A Journal for the History and Philosophy of Science 4(1): 138-147.

Compton, Bradley Wendell. 2009. The Domain Shared by Computational and Digital Ontology: a Phenomenological Exploration and Analysis. Electronic Theses, Treatises and Dissertations. Paper 3484, Florida State University.

Eldred, Michael. 2013. "Reputation in the Cyberworld", International Review of Information Ethics 19: 4-11.

Eldred, Michael. 2011 [2009]. The Digital Cast of Being: Metaphysics, Mathematics, Cartesiansim, Cybernetics, Capitalism, Communication. Gazelle Books Services. http://Arte-fact.org/dgt/cast.pdf

[ERCIT] European Research Cluster on the Internet of Things. 2012. The Internet of Things 2012 - New Horizons. Smith, Ian G. (ed.) Halifax, UK: New Horizons.

Floridi, Luciano \& Sanders Jeff W. 2004. "On the Morality of Artificial Agents", Minds and Machines 14(3): 349-379. 
Floridi, Luciano. 2011. "On the Morality of Artificial Agents", In Machine ethics, M. Anderson and S. L. Anderson (Eds.), Cambridge University Press, pp. 184-212.

Gettier, Edmund. 1963. "Is Justified True Belief Knowledge?", Analysis 23(6): 121-123.

Goldberg, Sanford C. 2012. "Epistemic extendedness, testimony, and the epistemology of instrument-based belief", Philosophical Explorations: An International Journal for the Philosophy of Mind and Action 15(2): 181-197.

Goldman, Alvin I \& Blanchard, Thomas. 2012. "Social Epistemology", In Oxford Bibliographies Online.

Han, Yu, Zhiqi, Shen, Leung, C., Chunyan Miao, \& Lesser, V.R. 2013. "A Survey of Multi-Agent Trust Management Systems", Access, IEEE 1(1): 35-50.

Hardwig, John. 1985. "Epistemic Dependence", The Journal of Philosophy 82(7): 335-349.

Hassan, M. M., Song, B., \& Huh, E. 2009. "A framework of sensor-cloud integration opportunities and challenges", In Proceedings of the 3rd International Conference on Ubiquitous Information Management and Communication, ICUIMC 2009, Suwon, Korea, January 15-16, pp. 618-626.

Houkes, Wybo. 2006. "Knowledge of Artefact Functions", Studies in History and Philosophy of Science 37: 102-113.

Humphreys, Paul. 2004. Extending Ourse/ves: Computational Science, Empiricism, and Scientific Method. Oxford: Oxford University Press.

Humphreys, Paul. 2009. "Network Epistemology", Episteme 6(2): 221-229.

Hutchins, Edwin. 1995. Cognition in the Wild. Cambridge, MA: MIT Press.

Johansson, Linda. 2013. "The Pragmatic Robotic Agent", Techné: Research in Philosophy and Technology 17(3): 295-315.

Johnson, Deborah G. 2006. "Computer systems: moral entities but not moral agents", Ethics and Information Technology 8(4): 195-204.

Jones, Karen. 1996. "Trust as an Affective Attitude", Ethics 107(1): 4-25

Kiran, Asle H. \& Verbeek, Peter-Paul. 2010. "Trusting Our Selves to Technology", Knowledge, Technology \& Policy 23(3-4): 409-427.

Kitcher, Philip. 1990. "The Division of Cognitive Labor", The Journal of Philosophy 87(1): 5-22.

Kletzl, Sebastian. 2014. "Scrutinizing thing knowledge", Studies in History and Philosophy of Science Part A 47: 118-123.

Kounelis, I.,Baldini, G., Neisse, R., Steri, G., Tallacchini, M., and Guimaraes Pereira, A. 2014. "Building Trust in the Human? Internet of Things Relationship", Technology and Society Magazine, IEEE 33(4): 73-80.

Kourken, Michaelian. 2014. "JFGI: From Distributed Cognition to Distributed Reliablism", Philosophical Issues, A Supplement to NOUS 24: 314-346.

Lahno, Bernd. 2004. "Three Aspects of Interpersonal Trust", Analyse \& Kritik 26: 30-47.

Latour, Bruno. 1992. "Where are the missing masses? The sociology of a few mundane artifacts", In Shaping Technology/Building Society; Studies in Sociotechnical Change, Bijker and Law (eds.). Cambridge: MIT Press, pp. 225-258.

Laudan, Rachel. 1984. The Nature of Technological Knowledge. Are Models of Scientific Change Relevant? Boston: Reidel.

Lawrance, Faith K. 2009. "Internet-Based Community Networks: Finding the Social in Social Networks", In Computing with Social Trust, Jennifer Golbeck (ed.), Springer, pp. 313-332.

Lehrer, Keith. 1995. "Knowledge and the Trustworthiness of Instruments", The Monist 78(2):156-170.

Longino, Helen. 2002. The Fate of Knowledge. Princeton: Princeton University Press.

Marsh, Stephen \& Briggs, Pamela. 2009. "Examining Trust, Forgiveness and Regret as Computation Concepts", In Computing with Social Trust, Golbeck, Jennifer (ed.). Springer, pp. 9-43.

McDowell, Ashley. 2002. "Trust and information: The role of trust in the social epistemology of information science", Social Epistemology 16(1): 51-63. 
Meijers, Anthonie W. M. \& Marc J. De Vries. 2009. "Technological Knowledge", In A Companion to the Philosophy of Technology, Olsen, J.K.B., Pedersen, S.A. and Hendricks, V.F. (eds). Chichester: Wiley-Blackwell, pp. 70-74.

Miller, Boaz \& Pinto, Meital. In progress. "Epistemic Equality".

Miller, Boaz \& Record, Isaac. 2013. "Justified Belief in a Digital Age: On the Epistemic Implications of Secret Internet Technologies", Episteme 10(2): 117-134.

Miller, Boaz. Forthcoming. "Social Epistemology", In The Internet Encyclopedia of Philosophy.

Nickel, Philip. J. 2013. "Trust in Technological Systems", In Norms in Technology, M. J. de Vries et al. (eds.). Dordrecht: Springer, pp. 223-237.

Nickel, Philip J., Franssen, Maarten, \& Kroes, Peter. 2010. "Can We Make Sense of the Notion of Trustworthy Technology?", Knowledge, Technology \& Policy 23(3-4): 429-444.

Pinyol, Isaac \& Sabater-Mir, Jordi. 2013. "Computational trust and reputation models for open multi-agent systems: a review", Artificial Intelligence Review 40: 1-25.

Pitt, Joseph C. 1983. "The epistemological engine", Philosophica 32(2): 77-95.

Pitt, Joseph C. 2007. "Speak to Me", Metascience 16: 51-59.

Pitt, Joseph C. 2010. "It's not about technology", Knowledge, Technology and Policy 23(3-4):445-454.

Primiero, Giuseppe. 2014. "On the Ontology of the Computing Process and the Epistemology of the Computed", Philosophy and Technology 27(3): 485-489.

Record, Isaac. 2013. "Technology and Epistemic Possibility", Journal for General Philosophy of Science 44: 319-339.

Shope, Robert K. 1983. The Analysis of Knowing: A Decade of Research. Princeton University Press.

Simon, Judith. 2010. "The Entanglement of Trust and Knowledge on the Web", Ethics and Information Technology 12:343-355.

Simpson, Thomas W. 2011. "E-Trust and Reputation", Ethics and Information Technology 13(1): 29-38.

Simpson, Thomas W. 2012. "What is Trust?", Pacific Philosophical Quarterly 93: 550-569.

Sosa, Ernest. 2006. "Knowledge: Instrumental and Testimonial", In The Epistemology of Testimony, J. Lackey and E. Sosa (eds.). Oxford: Oxford University Press, pp. 116-123.

Stankovic, J.A. 2014. "Research Directions for the Internet of Things", Internet of Things Journal, IEEE 1(1): 3-9.

Steup, Matthias. 2014 [2005]. "Epistemology", In The Stanford Encyclopedia of Philosophy, Edward N. Zalta (ed.). http://plato.stanford.edu/archives/spr2014/entries/epistemology

Tavani, Herman T. 2014. "Levels of Trust in the Context of Machine Ethics", Philosophy and Technology, Published Online 3 May 2014.

Tonkens, Ryan. 2009. "A Challenge for Machine Ethics", Minds And Machines: Journal For Artificial Intelligence, Philosophy, And Cognitive Science 19(3): 421-438.

Torrance, Steve. 2011. "Machine ethics and the idea of a more-than-human moral world", In Machine Ethics, M. Anderson and S. Anderson (Eds.). Cambridge Univ. Press, pp. 115-137.

van den Dam, Rob. 2013. "Internet of Things: The Foundational Infrastructure for a Smarter Planet", In Internet of Things, Smart Spaces, and Next Generation Networking, Lecture Notes in Computer Science Volume 8121, pp. 1-12.

Wagenknecht, Susann. 2014. "Four Asymmetries Between Moral and Epistemic Trustworthiness", Social Epistemology Review and Reply Collective 3(6): 82-86.

Wallach, Wendell \& Allen, Colin. 2009. Moral Machines: Teaching Robots Right from Wrong. Oxford: Oxford University Press.

Winner, Langdon. 1985. "Do artifacts have politics?", In The social shaping of technology, Mackenzie and Wajcman (eds.). Milton Keynes: Open University Press.

Wright, Stephen. 2010. "Trust and Trustworthiness", Philosophia 38: 615-627. 
Yuriyama, M. \& T. Kushida. 2010. "Sensor-Cloud Infrastructure - Physical Sensor Management with Virtualized Sensors on Cloud Computing", NBiS: 1-8. 